\title{
Hypothermia and mortality and morbidity. An epidemiological analysis
}

\author{
Bernadette Herity, Leslie Daly, Geoffrey J Bourke, Jacqueline M Horgan
}

\begin{abstract}
Study objective-The aim was to identify socioeconomic variables associated with deaths and hospital admissions due to hypothermia and to quantify the risk due to ambient outside temperature.

Design-The study was a survey of deaths and hospital admissions due to hypothermia (ICD 991.6), for the period 1979-85 inclusive, identified from death certificates and Hospital Inpatient Enquiry (HIPE) data.

Setting-The study included all deaths and hospital admissions due to hypothermia (1979-85) in the 26 counties of the Republic of Ireland, population 3.5 million.
\end{abstract}

Subjects-All deaths coded during the study period as being due to hypothermia and all persons admitted to hospital during the study period for whom hypothermia was recorded as a discharge diagnosis in HIPE data.

Measurements and main resultsDemographic data and date of death/ diagnosis were obtained from both data sets. Complete national temperature records were obtained from the meteorological service and a temperature was assigned to each case representing ambient outside temperature at which hypothermia developed. Risk of hypothermia at a given temperature was obtained by dividing the number of cases at that temperature by the appropriate person-years of exposure of the entire national population. Incidence of and mortality from hypothermia doubled with each $5^{\circ} \mathrm{C}$ and $4^{\circ} \mathrm{C}$ fall in temperature respectively; the majority of deaths and hospital admissions occurred between October and March. Incidence and mortality increased with age and men had $30 \%$ higher case fatality than women. Single men had four times the incidence and 6.5 times the mortality, and single women had double the incidence and four times the mortality of married men and women respectively. Low population density was also an important risk marker.

Conclusions-The risk of hypothermia due to ambient outside temperature has been quantified and a high risk group was identified. A combination of statutory support measures and good neighbourliness could prevent illness and deaths from hypothermia.
Elderly people are particularly vulnerable to hypothermia which is defined as a core body temperature of less than $35^{\circ} \mathrm{C}\left(95^{\circ} \mathrm{F}\right)$ caused by exposure to environmental cold. ${ }^{1}$ A report of the Royal College of Physicians, London, ${ }^{2}$ identified those aged less than one and over 65 years as being at highest risk. Alderson ${ }^{3}$ reviewed the literature on seasonal mortality and quoted an unpublished Department of Health and Social Security report of 1973 which sugested that those who died from hypothermia were socially different from the rest of the population; a higher proportion was female, single or divorced, unemployed, died in hospital, and had informants who were not relatives. Since there is a dearth of epidemiological information relating to hypothermia this study was undertaken to identify sociodemographic data associated with deaths and hospital admissions due to hypothermia and to quantify the risk due to outside ambient temperature.

\section{Methods}

Cases of hypothermia in the Republic of Ireland resulting in death or a hospital admission were identified for the years 1979-1985. The choice of 1979 as the starting point of the study corresponds to the changeover to the 9 th edition of the International Classification of Diseases Injuries and Causes of Death (ICD). ${ }^{4} \mathrm{~A}$ copy of the death certificate was obtained for each death occurring during the study period which was registered due to hypothermia (ICD 991.6). Only one cause of death is registered by the Central Statistics Office (CSO) but other causes of death recorded on the death certificates under any of three headings were noted for the purposes of this study: I (a) (disease or condition directly leading to death), I (b/c) (antecedent causes), and II (other significant conditions). The Hospital Inpatient Enquiry (HIPE) computer database was used to identify cases admitted to hospital during the study period when the discharge diagnosis included hypothermia. In Ireland, the Hospital Inpatient Enquiry is estimated to cover approximately $80^{\circ}$ o of hospital admissions and includes data from all the acute hospitals; the majority of private and some district hospitals do not make returns to the HIPE. Basic patient information and details of the patient's hospital stay, including ICD codes for up to four discharge diagnoses, are recorded. The following data were extracted: from death certificates, hospital where relevant, date of death, and whether or not an inquest was held; from HIPE records, hospital, date of admission, date of discharge, and discharge status (alive/dead). Details of age, sex, marital status, county of residence, and any recorded diagnoses or causes of 
death other than hypothermia were available from both sources.

Hypothermia rates were based on population data from the 1981 census $^{5}$ and age standardisation was used by the indirect method using total hypothermia rates as standard. Comparison with national all cause mortality was based on deaths occurring in $1983 .{ }^{6} \mathrm{~A}$ case fatality rate was defined as the number of deaths from hypothermia as a percentage of the total number of cases. Computer tapes of hourly temperature recordings at 14 weather stations throughout the county were obtained for 1979-85 inclusive. Mean daily temperature in each county for each day of the seven year study period was estimated from averages of the readings in the weather stations in or nearest to the county in question. Using these daily figures a temperature was assigned to each case on the basis of county of residence and date of admission (all Hospital Inpatient Enquiry cases) or date of death (deaths without an HIPE record of prior hospital admission). These data are taken to represent the ambient outside temperature at which hypothermia developed in those studied.

In order to analyse the risk of hypothermia in relation to temperature, person-years of exposure to different temperature ranges were estimated. For example in County Donegal there were 283 days $(0.77$ years) in the seven year study period when mean temperature was between 0 and $4^{\circ} \mathrm{C}$. The 1981 population of Donegal was 125000 giving $0.77 \times 125000=96250$ person years of exposure at this temperature. These person-years of exposure were calculated for each county and then summed over all counties. The risk of hypothermia at a given temperature was obtained by dividing the number of cases at that temperature by the appropriate person-years of exposure.

\section{STATISTICAL EVALUATION}

For the most part statistical analysis was based on a confidence interval approach using $95 \%$ levels. Confidence intervals (CI) for rates and percentages were based on the Poisson and the binomial distributions respectively. ${ }^{7}$ Statistical significance at a $5 \%$ level was inferred from non-overlapping confidence intervals. The Edward's test ${ }^{8}$ was used to determine the significance of seasonal trends and Poisson regression ${ }^{9}$ was employed to relate hypothermia risk to prevailing temperature.

\section{Results}

A total of 435 deaths from hypothermia was recorded in 1979-1985. Two hundred and nine of these were identified from death certificates. Of these 209 deaths, 88 occurred outside hospital, and 23 occurred in hospitals not covered by the Hospital Inpatient Enquiry scheme. The remaining 98 persons were certified as dying from hypothermia in a hospital which reported HIPE data (table I).

On 93 death certificates $(44.5 \%)$ more than one cause of death was recorded. Hypothermia (991.6) was recorded under $I$ (a) in 36 cases and under I (b) $/(c)$ in 57 . Where hypothermia was recorded under I (a), the majority (22 of 26) causes under I (b) $/$ (c) were antecedent causes, namely alcohol (12), falls/accident (8), gastric haemorrhage (1) and physical handicap (1); the other causes noted were exposure (2), malnutrition (1), and weakness (1). When hypothermia was recorded under I (b) the causes noted under I (a) tended to be mode of dying, eg, pneumonia, cardio/respiratory failure, pulmonary oedema etc, and in nine cases antecedent causes were entered under I (c) [alcohol (5), fall (4)]. In general additional causes under II (22 in total) were diagnoses of chronic illness reflecting the state of health of the predominantly elderly population who die from hypothermia, although alcohol/alcoholic liver disease was recorded in three and fall/fracture of hip in two cases.

From the Hospital Inpatient Enquiry records 273 patients were identified as dying in hospital with a diagnosis of hypothermia. Forty seven of these were successfully matched with the death certificates (table I); thus of 324 total hypothermia deaths in HIPE hospitals identified in this study, $51(15.7 \%)$ failed to be recorded in the HIPE system and $226(69 \cdot 8 \%)$ could not be matched with a death certificate.

\begin{tabular}{|c|c|c|c|}
\hline Source & $n$ & Place of death & $n$ \\
\hline Death certificates only & 162 & $\begin{array}{l}\text { Not in hospital } \\
\text { In non-HIPE hospital } \\
\text { In HIPE hospital }\end{array}$ & $\begin{array}{l}88 \\
23 \\
51\end{array}$ \\
\hline $\begin{array}{l}\text { Death certificates } \\
\text { and HIPE } \\
\text { HIPE only }\end{array}$ & $\begin{array}{r}47 \\
226\end{array}$ & $\begin{array}{l}\text { In HIPE hospital } \\
\text { In HIPE hospital }\end{array}$ & $\begin{array}{r}47 \\
226\end{array}$ \\
\hline Total & 435 & Total & 435 \\
\hline $\begin{array}{l}\text { Total: death certificates } \\
\text { Total: HIPE }\end{array}$ & $\begin{array}{l}209 \\
273\end{array}$ & $\begin{array}{l}\text { Total: hospital } \\
\text { Total: HIPE hospital }\end{array}$ & $\begin{array}{l}347 \\
324\end{array}$ \\
\hline
\end{tabular}

From the HIPE data, 857 patients who had a clinical diagnosis of hypothermia were identified as having been discharged alive. The total study group is thus 1292 hypothermia cases with 435 $(33.7 \%)$ deaths and $857(66.3 \%)$ survivors. There is no precedence accorded to the (up to) four diagnoses recorded for hospital admissions in HIPE. There was a total of 1312 diagnoses other than hypothermia recorded for the 1130 patients identified through this source; $953(72 \cdot 6 \%)$ of these diagnoses fell into six of the 17 major ICD categories: diseases of the circulatory system $(22.0 \%)$; respiratory system $(16.9 \%)$; mental disorders $(9.5 \%)$; endocrine, nutritional, and metabolic diseases $(9 \cdot 1 \%)$; ill defined conditions $(8.2 \%)$; and injury and poisoning $(6 \cdot 9 \%)$.

The analysis concentrates on three factors: incidence based on all cases, mortality based on deaths, and case fatality rates defined as the proportion of cases who died. Incidence and mortality rates are presented as annual rates per million of the population or per million personyears.

Table II presents these rates by age and sex. Incidence increased with age but to a lesser extent than mortality. Case fatality was three times greater in those aged 70 or above compared to those aged less than $50 \quad(p<0.05)$. The hypothermia mortality gradient with age was steeper than that for national all cause mortality rates $(72 \%$ of hypothermia deaths were in those 
Table II Age and sex specific incidence, mortality and case fatality rates for hypothermia (95\% CI in parentheses)

\begin{tabular}{|c|c|c|c|c|c|}
\hline & $\begin{array}{l}\text { No of } \\
\text { Cases }\end{array}$ & $\begin{array}{l}\text { No of } \\
\text { deaths }\end{array}$ & $\begin{array}{l}\text { Annual incidence } \\
\text { (per million) }\end{array}$ & $\begin{array}{l}\text { Annual mortality } \\
\text { (per million) }\end{array}$ & $\begin{array}{l}\text { Case fatality rate } \\
\left(\begin{array}{c}o \\
0\end{array}\right)\end{array}$ \\
\hline $\begin{array}{l}\text { Sex } \\
\text { Male } \\
\text { Female }\end{array}$ & $\begin{array}{l}639 \\
653\end{array}$ & $\begin{array}{l}244 \\
191\end{array}$ & $\begin{array}{ll}52 \cdot 8 & (48 \cdot 8-57 \cdot 0) \\
54 \cdot 4 & (50 \cdot 3-58 \cdot 8)\end{array}$ & $\begin{array}{ll}20 \cdot 2 & (17 \cdot 7-22 \cdot 9) \\
15 \cdot 9 & (13 \cdot 7-18 \cdot 3)\end{array}$ & $\begin{array}{ll}38 \cdot 2 & (34 \cdot 4-42 \cdot 1) \\
29 \cdot 3 & (25 \cdot 7-32 \cdot 9)\end{array}$ \\
\hline $\begin{array}{c}\mathrm{Age}^{\mathrm{a}} \text { (year } \\
<49 \\
50-69 \\
70+\end{array}$ & $\begin{array}{l}\text { s) } \\
203 \\
304 \\
736\end{array}$ & $\begin{array}{r}27 \\
93 \\
313\end{array}$ & $\begin{array}{rc}11 \cdot 0 & (9 \cdot 5-12 \cdot 6) \\
75 \cdot 9 & (67 \cdot 6-84 \cdot 9) \\
447 \cdot 4 & (415 \cdot 7-480 \cdot 9)\end{array}$ & $\begin{aligned} 1 \cdot 5 & (1 \cdot 0-2 \cdot 1) \\
23 \cdot 2 & (18 \cdot 7-28 \cdot 4) \\
190 \cdot 3 & (169 \cdot 8-212 \cdot 6)\end{aligned}$ & $\begin{array}{l}13 \cdot 3(9 \cdot 0-18 \cdot 8) \\
30 \cdot 6(25 \cdot 5-36 \cdot 1) \\
42 \cdot 5(38 \cdot 9-46 \cdot 2)\end{array}$ \\
\hline Total & 1292 & 435 & $53.6 \quad(50.7-56.6)$ & $18 \cdot 1 \quad(16 \cdot 4-19 \cdot 8)$ & $33 \cdot 7(31 \cdot 1-36 \cdot 3)$ \\
\hline
\end{tabular}

${ }^{a}$ Missing in 49 cases including two deaths.

Table III Standardised incidence ratios ( $S I R$ ), standardised mortality ratios (SMR) for hypothermia ( $95 \%$ CI in parentheses)

\begin{tabular}{|c|c|c|c|c|c|}
\hline Sex & $\begin{array}{l}\text { Marital } \\
\text { status }\end{array}$ & $\begin{array}{l}\text { No of } \\
\text { cases }^{2}\end{array}$ & $\begin{array}{l}\text { No of } \\
\text { deaths } \mathrm{s}^{\mathrm{a}}\end{array}$ & SIR & $S M R$ \\
\hline \multirow[t]{2}{*}{ Male } & $\begin{array}{l}\text { Married } \\
\text { Widowed } \\
\text { Single }\end{array}$ & $\begin{array}{r}153 \\
79 \\
371\end{array}$ & $\begin{array}{r}46 \\
37 \\
158\end{array}$ & $\begin{aligned} 48 & (40-57) \\
100 & (78-127) \\
181 & (158-206)\end{aligned}$ & $\begin{aligned} 35 & (25-48) \\
97 & (67-137) \\
226 & (184-277)\end{aligned}$ \\
\hline & All male & 603 & 241 & $100-$ & $100-$ \\
\hline \multirow[t]{4}{*}{ Female } & Married & 125 & 20 & $62 \quad(51-75)$ & $35 \quad(21-56)$ \\
\hline & Widowed & 254 & 98 & $105(91-122)$ & $116(90-149)$ \\
\hline & Single & 243 & 71 & $135(116-157)$ & $148(111-195)$ \\
\hline & All female & 622 & 189 & 100 & 100 \\
\hline
\end{tabular}

a 67 cases including five deaths with missing age or marital status

Table IV Distribution of cases and deaths by season

\begin{tabular}{lccccc}
\hline Month & $\begin{array}{l}\text { No of } \\
\text { cases }\end{array}$ & $o_{o}$ & $\begin{array}{l}\text { No of } \\
\text { deaths }\end{array}$ & \multicolumn{1}{c}{${ }^{\circ}$} & $\begin{array}{l}\text { Case fatality } \\
\left.\text { rate }{ }^{\circ}{ }_{o}\right)\end{array}$ \\
\hline Jan-Mar & 573 & $44 \cdot 4$ & 234 & $53 \cdot 8$ & $40 \cdot 8^{\circ}{ }^{\circ}$ \\
Apr-June & 208 & $16 \cdot 1$ & 49 & $11 \cdot 2$ & $23 \cdot 6^{\circ}{ }^{\circ}$ \\
Jul-Sep & 145 & $11 \cdot 2$ & 26 & $6 \cdot 0$ & $17 \cdot 9^{\circ}$ \\
Oct-Dec & 366 & $28 \cdot 3$ & 126 & $29 \cdot 0$ & $34 \cdot 4^{\circ}{ }^{\circ}$ \\
Total & 1292 & $100 \cdot 0$ & 435 & $100 \cdot 0$ & $33 \cdot 7^{\circ}{ }_{0}$ \\
\hline
\end{tabular}

Table $V$ Hypothermia incidence, mortality, and case fatality rates by ambient outside temperature (95\% CI in parentheses)

\begin{tabular}{lrccccc}
\hline $\begin{array}{l}\text { Temperature } \\
\left({ }^{\circ} \mathrm{C}\right)\end{array}$ & $\begin{array}{l}\text { No of } \\
\text { cases }\end{array}$ & $\begin{array}{l}\text { No of } \\
\text { deaths }\end{array}$ & $\begin{array}{l}\text { Annual incidence } \\
\text { per million }\end{array}$ & $\begin{array}{l}\text { Annual mortality } \\
\text { per million }\end{array}$ & $\begin{array}{l}\text { Case fatality } \\
\left({ }^{o}{ }_{0}\right)\end{array}$ \\
\hline$<-1$ & 71 & 31 & $264 \cdot 1(206 \cdot 3-333 \cdot 2)$ & $115 \cdot 3(78 \cdot 4-163 \cdot 7)$ & $43 \cdot 7(31 \cdot 9-56 \cdot 0)$ \\
$0-4$ & 371 & 154 & $109 \cdot 1$ & $(98 \cdot 3-120 \cdot 8)$ & $45 \cdot 3(38 \cdot 4-53 \cdot 0)$ & $41 \cdot 5(36 \cdot 5-46 \cdot 7)$ \\
$5-9$ & 497 & 162 & $60 \cdot 7$ & $(55 \cdot 4-66 \cdot 2)$ & $19 \cdot 8(16 \cdot 8-23 \cdot 1)$ & $32 \cdot 6(28 \cdot 5-36 \cdot 9)$ \\
$10-14$ & 278 & 78 & $31 \cdot 9$ & $(28 \cdot 3-35 \cdot 9)$ & $9 \cdot 0(7 \cdot 1-11 \cdot 2)$ & $28 \cdot 1(22 \cdot 9-33 \cdot 7)$ \\
$15+$ & 75 & 10 & $21 \cdot 3(16 \cdot 7-26 \cdot 7)$ & $2 \cdot 8(1 \cdot 4-5 \cdot 2)$ & $13 \cdot 3(6 \cdot 6-23 \cdot 2)$ \\
Total & 1292 & 435 & $53 \cdot 6(50 \cdot 7-56 \cdot 6)$ & $18 \cdot 1(16 \cdot 4-19 \cdot 8)$ & $33 \cdot 7(31 \cdot 1-36 \cdot 3)$ \\
\hline
\end{tabular}

aged 70 or older compared to $64 \%$ of all deaths). Males and females had a similar incidence but case fatality was $30 \%$ higher in males.

In table III age standardised incidence and mortality ratios are presented by marital status. For each sex the incidence and mortality ratios show a significant trend increasing from married to single persons. This hypothermia mortality gradient is much steeper than that for all cause mortality, for which the age and sex standardised ratios are 86, 107, and 112 in the married, widowed, and single respectively (total population standardised mortality ratio $=100$ ).

As would be expected, hypothermia mortality and incidence showed large seasonal variations and the case fatality rate was also significantly higher in winter months (table IV). Using Edward's test ${ }^{8}$ on the monthly figures, a highly significant seasonal trend was seen (all cases: $\chi^{2}=406.3 ; \quad \mathrm{df}=2 ; \quad \mathrm{p}<0.0001 ;$ mortality: $\left.\chi^{2}=332.3 ; \quad \mathrm{df}=2 ; \mathrm{p}<0.0001\right)$. The highest numbers of both cases (280) and deaths (120) were observed in January and the lowest in July (38 cases and five deaths).
Table $\mathrm{V}$ shows the distribution of cases and deaths by temperature at hospital admission or death. When rates per million person years of exposure are examined the sharp increase of incidence and mortality with temperature fall is seen. Using Poisson regression it was estimated that hypothermia incidence doubled for each $5.6^{\circ} \mathrm{C}$ fall in temperature and that mortality doubled for each $4 \cdot 1^{\circ} \mathrm{C}$ fall.

The geographical distribution of hypothermia incidence is shown in fig 1 for the 27 administrative areas of the Republic of Ireland, with the cut off levels determined on the basis of quartiles. The highest rates are seen in the north west and west of the country. To some extent this geographical variation in hypothermia incidence can be explained by between county variations in

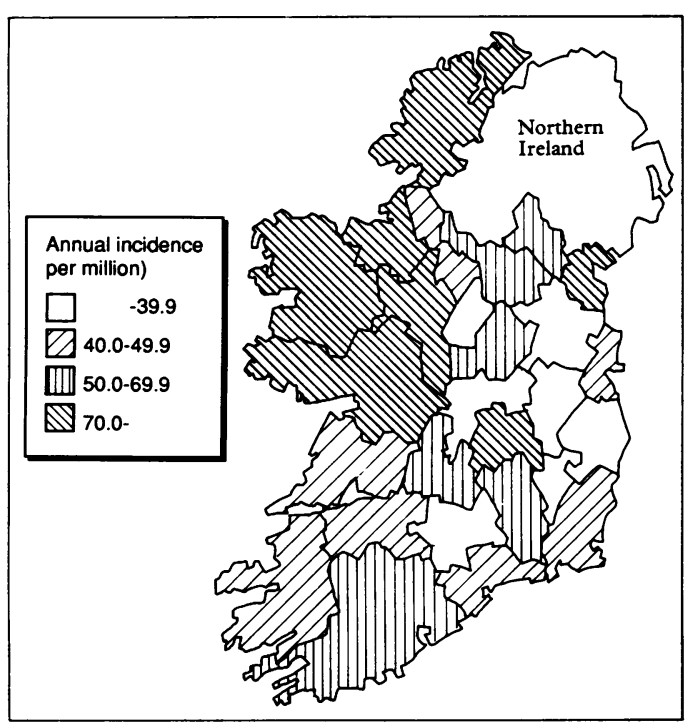

Figure 1 Geographical distribution of hypothermia incidence.

temperature but a linear regression of the county rates versus average annual county temperature was not significant. Figure 2 shows the relationship between the annual hypothermia incidence in a county and the density of population in that county. With one exception counties with high population densities tended to have low rates of hypothermia. Annual hypothermia incidence per million in counties with a population of 33 persons per square kilometre (the median) or less is $67.9\left(95^{\circ}{ }_{0} \mathrm{CI}\right.$ $62 \cdot 0-74 \cdot 2)$ compared to $47 \cdot 6\left(95^{\circ}{ }_{0}\right.$ CI $\left.44 \cdot 4-51 \cdot 0\right)$ in counties with densities above 33 persons $/ \mathrm{km}^{2}$. Thus the geographical variation in hypothermia incidence seems related more to population density than to average temperature, which was confirmed by multiple regression of the county rates against both factors. The Poisson regression analysis of the rates against actual temperature on the day of death did not adjust for county differences. A very similar picture is seen when mortality is examined.

\section{Discussion}

This study confirms what Alderson ${ }^{2}$ found in the UK, namely that official statistics on hypothermia need to be interpreted with caution. In the present study $70 \%$ of patients identified as dying in 


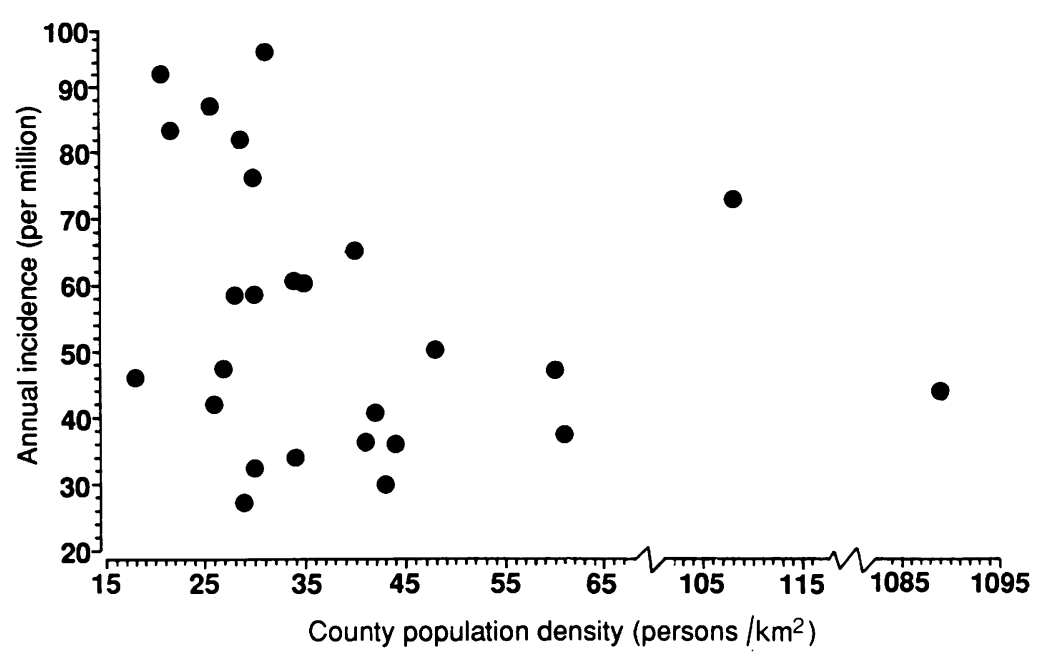

Figure 2 Annual hypothermia incidence and county population density.

hospital with a discharge diagnosis which included hypothermia could not be matched with a death certificate which recorded hypothermia as a cause of death. Conversely 51 persons certified as dying from hypothermia in hospitals which return Hospital Inpatient Enquiry data did not have a discharge diagnosis of hypothermia recorded. There are thus major discrepancies between HIPE and national mortality statistics. Matching was undertaken on the basis of age, sex, date of death, county of residence, and hospital, since the identity of HIPE patients is not revealed without specific permission from their doctors, and it is possible that incorrect computer coding may have reduced the completeness of matching. However, the two data sets were carefully scrutinised and if there was agreement on four of the five criteria and miscoding in one item could explain the difference, a match was accepted.

The reasons for the major discrepancies in the recording and certification of deaths from hypothermia in this study need further consideration. Alderson ${ }^{3}$ also found marked discrepancies between death certification and hospital records. It is suggested ${ }^{10}$ that since the word hypothermia has come into popular usage it may be regarded as being synonymous with "neglect" and that consequently doctors may be reluctant to use it in certifying deaths. In fact the term "exposure" was used on a number of death certificates and was coded as hypothermia. It is proposed to follow up the discrepancies revealed by the current research.

Although incidence figures are based on hospital admissions and mortality only, and cases admitted to hospitals not participating in the Hospital Inpatient Enquiry were not completely ascertained, this study is the most complete national investigation ever reported. Though the hypothermia rates quoted are likely to be underestimates there is no reason to suspect bias in the epidemiological associations found.

In this study there were some problems in assessing local temperatures since computerised daily records of temperature are available for only 14 weather stations in the Republic of Ireland. County of residence was taken to determine the location of a case, and temperature at which hypothermia occurred was estimated on the basis of the mean temperature on the day in question recorded at the nearest weather station. In addition these records are based on readings taken in the open and may not precisely reflect the temperature of a dwelling house if hypothermia occurred inside. However, the data used are the only available indicators of the temperature at which a death or hospital admission due to hypothermia occurred. Using these data the hypothermia risk variation with prevailing temperature has been quantified for the first time; incidence and mortality doubled with each $5^{\circ} \mathrm{C}$ and $4^{\circ} \mathrm{C}$ fall in temperature respectively.

Eighty three percent of deaths and $73 \%$ of all cases of hypothermia occurred between October and March. In Alderson's review of deaths in the UK with mention of hypothermia for 1971-83, over $80 \%$ occurred in the six months between October and March, and in a study of computerised inquest records in England ${ }^{11}$ the greatest proportion $(93 \%)$ of deaths from hypothermia occurred between December and March.

Incidence of hypothermia in men and women was similar, but men had a $30 \%$ increased risk of dying compared with women; old age increased incidence and case fatality in both sexes. Marital status was also strikingly related to incidence and mortality, with single persons having the highest and married persons the lowest risks. It would seem only common sense to infer that since single and widowed persons are more likely to live alone their chances of being found early if they collapse outside or become hypothermic indoors are much less than the married person, who is likely to live with a spouse. There was little difference between men and women for risk related to marital status. Additional causes of death, namely alcohol $(9.5 \%)$, falls/accidents $(6 \cdot 7 \%)$, and chronic illness $(10.5 \%)$, were identified in nearly $27 \%$ of death certificates studied. This is a much lower proportion than in the UK study of inquests, ${ }^{11}$ where 35 of 43 deaths were recorded as being secondary to other conditions.

The geographical distribution of risk from hypothermia (fig 1) shows that the north west and west of the country were the highest risk areas for hypothermia, but the association of county hypothermia rates with average (over entire study period) county temperatures was not significant. This is most likely due to the fact that county differences in average temperature do not reflect the actual situation since extremes of temperature are not accounted for. However there is a highly significant association of deaths from hypothermia with population density (fig 2 ). This again sugests that isolation is an important factor in hypothermia, since persons who become immobilised in cold weather are less likely to be discovered quickly if they live in isolated rural areas.

For the study period hypothermia accounted for less than $10 \%$ of all cause national mortality in the $70+$ age group; nevertheless these deaths are important because they are preventable. The old who live alone are at highest risk. Many elderly people spend most of their time at home and therefore need to heat their houses for extensive 
periods, unlike those in employment who are kept warm at their employer's expense for most of the day. Homes of elderly people are less likely to have central heating; a study carried out by the Office of Population Censuses and Surveys ${ }^{12}$ in the UK showed that $42 \%$ of the elderly lived alone and that $34 \%$ of elderly couples had no central heating; they were also less likely to have adequately insulated homes. The proportion in Ireland with central heating and properly insulated housing is likely to be even lower because of the large numbers living in rural areas.

The health promotion approach incorporating health education, specific preventive measures and public policy directed at particular aspects of the problem would undoubtedly be effective in reducing this preventable illness and mortality. Education of the elderly and their families by making available practical advice on how to keep warm in very cold weather would be a first step. Booklets and leaflets which contain advice on avoiding hypothermia have been found to be useful and can be made widely available through local health professionals, committees for the care of the elderly, pharmacies, post offices, public libraries, and other suitable outlets. In the UK, Age Concern and Help the Aged, both voluntary agencies, have published such leaflets and the local citizens' advice bureaus also provide information. The mass media can also be influential in highlighting the problem particularly through individual radio and television presenters and magazine programmes which have a wide appeal. This method could be particularly helpful in alerting public attention to the risks of hypothermia during sudden episodes of severe cold.

Adequate statutory support for preventive measures both in the long term and in acute circumstances is a prerequisite for a reduction in illness and deaths. The Social Services in many contries provide subsidies for fuel to those assessed as being in need but these may not be adequate in very cold winters, and indeed are not fully availed of even by those who are entitled to such support. Despite the best efforts of both voluntary and statutory services some persons at risk do not claim these supplementary benefits, either through lack of knowledge or for reasons of pride, and every effort must be made to persuade them to do so. Inadequate housing is common among the elderly poor, and improved housing is another basic long term preventive measure.
Short term emergency services are essential during spells of particularly cold weather. The social services should be able to supply additional blankets and portable heaters at short notice to households at risk; cooperation with voluntary agencies could ensure a quick response in emergencies. An innovative approach was taken in the UK during the winter of 1987-1988 when the governemnt funded a national "Winter Warmth Line", ie, a freephone telephone line where persons were referred to various sources of help and advice.

Health professionals working in the community should be aware of those who may be at risk during sudden falls in temperature and should be particularly vigilant when they occur. Specifically because of the risks identified in this study neighbours should be encouraged to check on those who live alone in isolated areas and to offer them transport where possible in cold weather. Those who develop hypothermia or die from it do so unnecessarily; a combination of professional vigilance, statutory and voluntary support, and good neighbourliness could prevent most of this avoidable morbidity and mortality.

We thank the staffs of the Central Statistics and General Register Office, Dublin, for mortality data; Mr John O'Gorman, Health Research Board, Dublin, for HIPE data; the staff of the Meteorological Service for computer tapes of national temperature records; $\mathrm{Dr}$ Nancy Hilliard and the staff of the Computer Centre of University College, Dublin, for data collection and computer facilities. Coal Distributers Ltd Dublin kindly provided financial support for the study.

1 Rango N. Old and cold: hypothermia in the elderly. Geriatrics 1980; 35: 93-6.

2 Royal College of Physicians of London. Committee on Accidental Hypothermia Report. London: Royal College of Physicians, 1966.

3 Alderson MR. Season and mortality. Health Trends 1985; 17: 87-95.

4 World Health Organization. Manual of the international classification of diseases, injuries and causes of death, 1975 revision. Geneva: World Health Organization, 1977

5 Central Statistics Office. Census of population of Ireland 1981, vol 1. Dublin: Stationery Office, 1982.

6 Central Statistics Office. Report on vital statistics, 1985. Dublin: Stationery Office, 1988

7 Gardner MJ, Altman DG. Statistics with confidence-confidence intervals and statistical guidelines. London: British Medical Journal, 1989.

$8 \mathrm{Edwards} \mathrm{JH}$. The recognition and estimation of cyclic trends. Ann Hum Genet 1961; 25: 83-7.

9 Frome EL, Checkowry M. Uses of Poisson regression models in estimating incidence rates and ratios. $\mathrm{Am} \mathcal{F}$ Epidemiol 1985; 121: 309-23.

10 Wicks M, Henwood M, Owen G The cold facts-a programme for action (Report). London: WACH, 1988.

11 Slater DN. Deaths from hypothermia: are current views on causative factors well founded? $B M \mathcal{F}^{\prime}$ 1988; 296: $1643-4$.

12 Office of Population Censuses and Surveys. General household survey 1985. London: HMSO, 1987.
. 